\title{
SENI TRADISI NUSANTARA GONDANG BUHUNSEBAGAI MEDIA PENDIDIKAN KARAKTER REMAJA DI KABUPATEN PANGANDARAN
}

\author{
Nia Emilda, Ai Juju Rohaeni, Wanda Listiani \\ Institut Seni Budaya Indonesia (ISBI) Bandung \\ Jl. Buah Batu No. 212 Bandung
}

\begin{abstract}
Pangandaran regency is one of the regencies in West Java province which has a diversity of art and culture that is continuously maintained its sustainability. One of the art traditions is Gondang Bubun. It is a traditional art that is maintained by the local community hereditary and has noble values that can be used as a medium of education characters for adolescents in Pangandaran Regency. This research uses qualitative method with case study approach which describes the process of art of Gondang Bubun tradition as a medium of adolescent education characters. The result of this research is Gondang Bubun art process as a media of educational characters; The supporting and inbibiting factors of Gondang Bubun tradition are as media of educational characters; and educational efforts of adolescent characters through the art of Gondang Bubun tradition.
\end{abstract}

Keywords: Gondang Bubun, Educational Characters, Adolescents

\section{PENDAHULUAN}

Pendidikan merupakan hak dari setiap manusia, karena dengan pendidikan manusia dapat mengembangkan potensi kemanusiaan yang dimilikinya. Pendidikan tidak hanya di lembaga formal saja, namun pendidikan dapat didapatkan di lembaga informal dan nonformal.

Lembaga-lembaga tersebut tidak bisa berdiri sendiri, karena lembaga satu membutuhkan lembaga lainnya. Setiap lembaga memiliki peran dan tanggung jawabnya masingmasing dalam proses pendidikan. Banyak upaya yang dilakukan dalam proses pendidikan, begitu halnya dengan pendidikan karakter, upaya yang bisa dilakukan dalam menyelenggarakan pendidikan karakter bagi remaja yang dapat dilakukan di berbagai lembaga atau lingkungan, serta pada berbagai bidang, salah satunya ialah melalui seni. Muatan nilai-nilailuhur yang ada pada suatu kesenian dapat dijadikan sebagai media pendidikan karakter bagi remaja.

Provinsi Jawa Barat dikenal sebagai provinsi yang memiliki keanekaragaman seni dan budaya, salah satunya di Kabupaten Pangandaran sebagai destinasi wisata di Provinsi Jawa Barat yang sangat menaruh perhatian terhadap pelestarian seni dan budaya. Ada beberapa seni tradisi yang masih dijaga kelestariannya secara turun-temurun yaitu seni Gondang Buhun.

Seni Gondang Buhun adalah seni tradisi yang mempertunjukkan proses pengolahan padi menjadi beras dengan menggunakan sarana lesung dan alu yang diiringi dengan kakawihan atau syair yang dinyanyikan secara bersama oleh pelaku seni tradisi Gondang Buhun.

Banyak nilai yang bisa dijadikan sebagai upaya pendidikan karakter yang terdapat dalam seni tradisi Gondang Buhun yaitu: kesabaran, 
kerja keras, kebersamaan, komunikatif, dan keteraturan. Meski yang menjadi pelaku seni tradisi Gondang Buhun merupakan perempuan yang sudah berumur, namun nilai-nilai luhur seni tradisi Gondang Buhun dapat diinternalisasikan pada remaja sebagai generasi muda yang akan meneruskan seni Gondang Buhun sebagai seni tradisi di Kabupaten Pangandaran.

Internalisasi nilai Gondang Buhun pada remaja perlu dilakukan untuk menjaga kelestarian Gondang Buhun sebagai seni tradisi serta menjaga nilai-nilai luhur dalam seni tradisi tersebut yang dapat dijadikan sebagai media pendidikan karakter bagi remaja.

\section{PENDEKATAN/ PERSPEKTIF}

Penelitian ini berkaitan dengan pendidikan karakter remaja melalui seni tradisi Gondang Buhun dengan fokus pada batasan masalah internalisasi nilai-nilai yang terdapat di dalamnya. Pembatasan fokus penelitian dimaksudkan agar penelitian tidak keluar dari pokok permasalahan.

Proses internalisasi nilai dalam penelitian ini merupakan proses penghayatan dan pengamalan nilai-nilai luhur dalam seni tradisi Gondang Buhun yang dapat diaplikasikan dalam kehidupan sehari-hari bagi remaja dan masyarakat secara luas.

Penelitian ini dilakukan berdasarkan asumsi-asumsi bahwa: 1) Pengaruh negatif dari globalisasi bisa melunturkan nilai-nilai tradisi yang luhur pada remaja; 2) Pewarisan nilai seni tradisi harus dilestarikan sebagai acuan hidup bagi generasi yang akan datang; dan 3) Penelitian dilakukan di Kabupaten Pangandaran karena kabupaten tersebut memiliki potensi parawisata alam dan kesenian yang menarik untuk diketahui dan dikembangkan.

Metode yang digunakan dalam penelitian ini adalah metode kualitatif dengan pendekatan studi kasus yaitu mendeskripsikan proses internalisasi nilai sebagai upaya pendidikan karakter bagi remaja melalui seni tradisi Gondang Buhun.

Adapun rancangan penelitian yang digunakan ialah 1) Tahap pra lapangan; 2) Tahap pekerjaan lapangan; 3) Tahap Analisis dan interpretasi data; 4) Tahap penarikan kesimpulan.

Tahap pra lapangan dilakukan untuk mengetahui kondisi dan situasi awal berkaitan dengan lokasi penelitian di Kabupaten Pangandaran, permasalahan yang ada berkenaan dengan karakter remaja dan pewarisan nilai-nilai seni tradisi Gondang Buhun, serta menghimpun beberapa sumber literatur terkait penelitian yang dilakukan.

Tahapan pekerjaan lapangan merupakan tahapan pengumpulan data yang diperoleh di lokasi penelitian dengan melakukan teknik observasi, wawancara, dan dokumentasi berkaitan dengan seni tradisi Gondang Buhun sebagai media pendidikan karakter remaja di Kabupaten Pangandaran.

Tahapan selanjutnya yang dilakukan ialah analisis dan interpretasi data yang diperoleh selama tahap pekerjaan lapangan di lokasi penelitian.

Setelah semua data dianalisis dan dinterpretasi oleh peneliti, maka tahapan 
selanjutnya ialah penarikan kesimpulan berkaitan dengan permasalahan yang diteliti.

Tahapan penelitian tersebut dimaksudkan sebagai panduan peneliti dalam melakukan penelitian untuk mendapatkan deskripsi tentang seni tradisi Gondang Buhun sebagai media pendidikan karakter bagi remaja.

\section{PEMBAHASAN}

\section{A. Seni Tradisi Gondang Buhun}

Kabupaten Pangandaran dikenal dengan seni tradisi Gondang Buhun yang masih bisa dijumpai hingga sekarang ini, namun tidak semua wilayah di Kabupaten Pangandaran memiliki kegiatan rutin melestarikan seni tradisi Gondang Buhun. Salah satu wilayah yang konsisten melestarikan seni Gondang Buhu ialah wilayah Kampung Badud. Kampung Badud merupakan kampung budaya yang berada di Kecamatan Cijulang khususnya di Desa Margacinta. Gondang Buhun dijaga kelestariannya secara turun-temurun, sehingga seni tradisi Gondang Buhun dapat dijumpai pada saat sekarang. Pelaku Gondang Buhun adalah kaum perempuan yang sudah berumur, oleh karena itu Pemerintahan Kabupaten Pangandaran bersama masyarakat mengupayakan pewarisan seni Gondang Buhun terhadap generasi muda, sehingga seni tradisi Gondang Buhun tidak mengalami kepunahan, namun pewarisan seni tradisi Gondang Buhun mengalami hambatan yaitu sulitnya menghasilkan irama yang teratur dari alu dan lesung, sehingga membutuhkan bimbingan dari pelaku Gondang Buhun yang ahli dalam hal tersebut. Hal itu menjadi tantangan bagi Pemerintah dan masyarakat setempat untuk terus mengupayakan pewarisan seni tradisi Gondang Buhun tehadap generasi muda.

Seni tradisi Gondang Buhun merupakan seni yang mempertunjukkan proses pengolahan padi menjadi beras, dengan menggunakan sarana lesung dan alu, dan diiringi dengan kakawihan atau syair yang dinyanyikan oleh pelaku Gondang Buhun.

Terdapat tiga unsur yang dimiliki oleh seni tradisi Gondang Buhun yaitu: alu, lesung, dan kakawihan (syair) yang dinyanyikan. Alu berfungsi sebagai penumbuk padi, lesung berfungsi sebagai wadah padi, dan kakawihan merupakan syair yang mengiringi para perempuan yang memainkan Gondang Buhun dalam pertunjukkan proses pengolahan padi menjadi beras.

Selain itu, pewarisan seni tradisi Gondang Buhun juga mengalami hambatan yaitu sulitnya menghasilkan irama yang teratur dari alu dan lesung, sehingga membutuhkan bimbingan dari pelaku Gondang Buhun yang ahli dalam hal tersebut. Hal itu menjadi tantangan bagi Pemerintah dan masyarakat setempat untuk terus mengupayakan pewarisan seni tradisi Gondang Buhun tehadap generasi muda.

Pemerintahan Desa Margacinta memiliki program rutin dalam melestarikan seni tradisi Gondang Buhun yaitu dengan melakukan latihan satu kali dalam satu minggu yang dipusatkan di Kampung Badud. Selain itu, Seni Gondang Buhun kampung Badud juga aktif 
mengikuti festival seni baik yang diselenggarakan oleh desa, kecamatan, kabupaten, ataupun menjadi kontingen kesenian mewakili Kabupaten Pangandaran di tingkat provinsi.
Gambar 2

Akses Jalan Menuju Kampung Badud Tidak Bisa Dilalui oleh Kendaraan Roda Empat (Sumber: Dokumentasi Penelitian, 2016)

Gambar 1.

Peneliti di depan Kantor Kepala Desa Margacinta Kecamatan Cijulang Kabupaten Pangandaran

(Sumber: Dokumentasi Penelitian, 2016)

Pemerintah Desa Margacinta mengupayakan pengembangan potensi seni dan budaya sebagai dukungan kepada Kabupaten Pangandaran yang dikenal sebagai kabupaten dengan destinasi pariwisata yang ada di Provinsi Jawa Barat.

Kampung Badud Desa Margacinta dijadikan sebagai sentral pengembangan seni budaya, baik Gondang Buhun maupun kesenian lainnya. Kampung Badud ini berjarak kurang lebih $7 \mathrm{KM}$ dari pusat pemerintahan desa, akses jalan yang belum memadai, membuat wilayah ini sulit dijangkau. Jalan bebatuan dan terjal menjadi hambatan ditambah dengan sekitar $2 \mathrm{KM}$ sebelum memasuki wilayah Kampung Badud, jalan tidak bisa dilalui oleh kendaraan roda empat, karena hanya bisa dilalui oleh kendaraan roda dua atau dengan berjalan kaki, serta juga harus melewati jembatan gantung.
Gambar 3

Peneliti dan Kepala Desa Margacinta melewati jalan menuju Kampung Badud (Sumber: Dokumentasi Penelitian, 2016)

Gambar 4.

Padepokan Badud di Kampung Badud sebagai tempat latihan seni Gondang Buhun dan seni tradisi lainnya

(Sumber: Dokumentasi Peneltian, 2016) 
Akses menuju dan keluar dari Kampung Badud tidak mudah, namun masyarakat khususnya pelaku seni tradisi Gondang Buhun tetap menjaga semangat dan konsisensi latihan dan memainkan pertunjukkan seni tradisi Gondang Buhun di luar Kampung Badud.

\section{B. Pendidikan Karakter Remaja}

Pendidikan karakter merupakan upaya untuk membangun jiwa yang baik pengembangan nilai-nilai yang dimiliki oleh manusia. Fakry Gaffar (Dharma Kesuma, dkk., 2011: 5) memberikan definisi pendidikan karakter ialah sebuah proses transformasi nilainilai kehidupan untuk ditumbuhkembangkan dalam kepribadian seseorang sehingga menjadi satu dalam kehidupan orang itu. Selain itu, T. Ramli (Asmani, 2013: 32) menjelaskan bahwa pendidikan karakter memiliki esensi dan makna yang sama dengan pendidkan moral dan akhlak. Tujuannya adalah untuk membentuk pribadi anak supaya menjadi manusia yang baik, yaitu warga masyarakat dan negara yang baik. Manusia, masyarakat, dan warga negara yang baik adalah menganut nilai-nilai soial tertentu yang banyak dipengaruhi oleh budaya masyarakat dan bangsanya.

Ada beberapa hal yang menjadi inti karakter, sebagaimana yang dijelaskan oleh oleh Budimansyah (2010: 1) bahwa "Inti karakter adalah kebajikan (goodness) dalam arti berpikir baik (thinking good), berperasaan baik (feeling good), dan berperilaku baik (behaving good).
Integrasi dari ketiga inti karakter tersebut harus dapat berjalan bersinergi untuk membangun karakter yang baik. Integrasi tersebut sangat diperlukan dalam penerapan pendidikan karakter, apalagi dalam menghadapi era globalisasi dengan segala dampak positif dan negatifnya, diperlukan generasi mudah yang berkarakter, yaitu generasi yang tangguh dan memiliki nilai-nilai luhur sehingga generasi muda dapat menjawab tantangan zaman, namun tidak tergerus oleh perubahan zaman itu sendiri.

Di samping tiga inti karakter tersebut, Thomas Lickona (Elmubarok, 2008: 110-111) menjelaskan tentang penjabaran aspek karakter yang terdiri daripengetahuan moral (moral knowing), perasaan moral (moral feeling), dan perilaku moral (action moral) yaitu:

Aspek Moral Knowing terdiri atas: 1) Moral Awerness; 2) Knowing Moral Values; 3) Perspective Taking; 4) Moral Reasoning; 5) Decision Making, dan 6) Self-Knowledge.

Aspek Moral Feeling terdiri dari beberapa hal, yaitu: 1) Conscience; 2) Self Esteem; 3) Emphaty; 4) Loving the Good; 5) Self-Control; dan 6) Humility.

Aspek Moral Action terdiri atas: 1) Kompetensi (Competence); 2) Keinginan (Will); dan 3) Kebiasaan (Habit).

Setiap penjabaran dari ketiga aspek tersebut berupaya membangun karakter yang baik yang bisa dimiliki oleh manusia. 
Dewasa ini telah dilakukan berbagai upaya pendidikan karakter baik di lingkungan keluarga, sekolah, maupun masyarakat. Persoalan karakter tidak hanya dibebankan pada satu bidang, namun semua bidang bisa ikut serta dalam mengupayakan pendidikan karakter bagi generasi muda, salah satunya ialah bidang seni budaya yang merupakan kekayaan yang dimiliki oleh Indonesia.

\section{Proses Internalisasi Karakter}

Upaya nyata telah dilakukan oleh pemerintah, baik Pemerintahan Desa, Kecamatan, maupun Kabupaten, hal ini dilihat dari kegiatan Karang Taruna, maupun kegiatankegiatan ekstrakurikler di lembaga pendidikan sudah berupaya untuk melakukan pewarisan seni tradisi Gondang Buhun terhadap generasi muda

Di samping upaya pemerintah, masyarakat setempat pun memiliki keasadaran dan kemauan yang tinggi untuk melestarikan seni tradisi Gondang Buhun, meskipun pada kenyataannya masih ada anggapan dari sebagian generasi muda yang menganggap bahwa seni tradisi Gondang Buhun sebagai seni yang kampungan yang tidak sesuai dengan generasi muda. Untuk itu pemerintah dan masyarakat setempat perlahan memberikan pemahaman kepada generasi muda dan melibatkan mereka untuk menjadi pelaku Gondang Buhun

Seni memiliki nilai-nilai yang dapat diinternalisasikan pada pelaku seni dan masyarakat secara luasdengan menghayati dan mengamalkan nilai-nilai yang terdapat dalam seni dalam kehidupan sehari-hari, pelaku seni dan
mBerkaitan dengan hal tersebut, seni tradisi Gondang Buhun juga menjadi salah satu seni yang mengupayakan proses internalisasi nilainilai luhur yang terdapat dalam seni tradisi Gondang Buhun.

Upaya pendidikan karakter melalui seni tradisi Gondang Buhun di Kabupaten Pangandaran ini didukung oleh pemerintah ${ }^{1}$. Upaya ini dilakukan karena begitu pentingnya pendidikan karakter bagi generasi muda yang bisa diupayakan melalui tiga bidang tersebut.

Terdapat beberapa nilai dalam seni Gondang Buhun, yaitu nilai kesabaran, kerja keras, kebersamaan, komunikatif, dan keteraturan. Kelima nilai tersebut diharapkan terinternalisasi pada pelaku seni tradisi Gondang Buhun dan dapat menjadi nilai yang dimiliki oleh masyarakat secara luas.

\section{Tabel 1:}

Nilai -nilai yang Terdapat pada Seni Tradisi Gondang Buhun

(Sumber: Dokumentasi Penelitian, 2016)

\begin{tabular}{|c|c|c|}
\hline $\begin{array}{c}\text { No } \\
\text {. }\end{array}$ & $\begin{array}{c}\text { Nilai Seni } \\
\text { Tradisi } \\
\text { Gondang } \\
\text { Buhun }\end{array}$ & Keterangan \\
\hline 1 & Kesabaran & $\begin{array}{l}\text { Kesabaran dalam } \\
\text { mengolah padi menjadi } \\
\text { beras yang menjadi }\end{array}$ \\
\hline
\end{tabular}

${ }^{1}$ Hal ini terbukti pada tahun ajaran 2016, Kabupaten Pangandaran mencanangkan pendidikan berkarakter yang meliputi bidang keagamaan, pramuka, dan seni budaya. Para remaja juga diikutsertakan pada pertunjukkan seni tradisi Gondang Buhun dalam mengisi kegiatan atau festival kesenian yang selenggarakan oleh Kabupaten Pangandaran. 


\begin{tabular}{|c|c|c|}
\hline & & $\begin{array}{l}\text { pertunjukkan dalam } \\
\text { seni tradisi Gondang } \\
\text { Buhun. }\end{array}$ \\
\hline 2 & Kerja keras & $\begin{array}{l}\text { Tenaga yang } \\
\text { dibutuhkan untuk } \\
\text { mengolah padi menjadi } \\
\text { beras. }\end{array}$ \\
\hline 3 & Kebersamaan & $\begin{array}{l}\text { - Seni tradisi Gondang } \\
\text { Buhun merupakan } \\
\text { seni yang } \\
\text { dipertunjukkan } \\
\text { secara bersama-sama; } \\
\text { - Irama alu dan lesung } \\
\text { serta kakawihan yang } \\
\text { dinyanyikan secara } \\
\text { bersama; } \\
\text { - Ajang berkumpul } \\
\text { sebelum dimulainya } \\
\text { suatu hajatan atau } \\
\text { pagelaran. }\end{array}$ \\
\hline 4 & Komunikatif & $\begin{array}{l}\text { Seni tradisi Gondang } \\
\text { Buhun merupakan } \\
\text { alat komunikasi. }\end{array}$ \\
\hline 5 & Keteraturan & 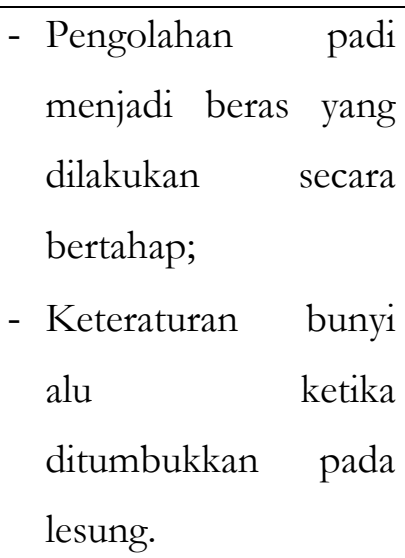 \\
\hline
\end{tabular}

Penjelasan tabel 1. Nilai-nilai yang terdapat pada Seni Tradisi Gondang Buhun dijabarkan sebagai berikut:
Nilai kesabaran dalam seni tradisi Gondang Buhun dapat ditunjukkan dengan proses pengolahan padi menjadi beras yang memerlukan kesabaran dari pelaku seni tradisi Gondang Buhun.

Nilai kerja keras dalam seni tradisi Gondang Buhun terlihat dari upaya untuk mengolah padi menjadi beras yang tidak mudah, memerlukan waktu dan tenaga yang mumpuni.

Nilai kebersamaan dalam seni tradisi Gondang Buhun terlihat dari proses pengolahan padi menjadi beras yang dilakukan secara bersama-sama, baik ketika alu ditumbukkan ke lesung, maupun ketika menyanyikan kakawihan atau syair secara bersama. Selain itu, bahwa pada awalnya seni tradisi Gondang Buhun merupakan ajang berkumpulnya kaum perempuan setiap sebelum suatu hajatan diselenggarakan.

Nilai komunikatif dalam seni tradisi Gondang Buhun ditunjukkan dari kakawihan atau syair yang dinyanyikan. Di samping itu, menurut sejarah bahwa seni tradisi Gondang Buhun pada zaman dahulu dijadikan sebagai alat komunikasi penanda akan diglar suatu hajatan.

Nilai keteraturan dan seni tradisi Gondang Buhun terlihat dari proses pengolahan padi menjadi beras yang dilakukan secara bertahap, demikian halnya keteraturan yang dihasilkan dari bunyi alu yang ditumbukkan ke lesung menghasilkan bunyi atau irama yang sangat teratur. 


\section{Gambar 5.}

Alu dan Lesung yang dijadikan sebagai sarana pertunjukkan seni tradisi Gondang Buhun.

(Sumber: Dokumentasi Penelitian, 2016)

\section{Gambar 6.}

Kepala Desa Margacinta Memberikan Arahan sebelum Pertunjukkan Gondang Buhun

Dimulai.

(Sumber: Dokumentasi Penelitian, 2016)
Gambar 8 .

Pertunjukkan Seni Tradisi Gondang Buhun

(Sumber: Dokumentasi Penelitian, 2016)
Gambar 9.

Wawancara Peneliti dengan bebera siswa SMKN Kabupaten Pangandaran

(Sumber: Dokumentasi Penelitian, 2016)

Gambar 7.

Beberapa Pelaku Seni Tradisi Gondang Buhun Mulai memukul Alu ke dalam Lesung Sebagai Penanda bahwa Pertunjukkan Seni Tradisi Gondang Buhun Akan Dimulai.

(Sumber: Dokumentasi Penelitian, 2016) 
Gambar 10.

Tempat Latihan Seni Tradisi Gondang Buhun Karang Taruna Sub Unit Dusun Margajaya Desa Margacinta Kecamatan Cijulang Kabupaten Pangandaran

(Sumber: Dokumentasi Penelitian, 2016)

\section{PENUTUP}

Secara umum seni tradisi Gondang Buhun dijadikan sebagai media pendidikan karakter bagi remaja di Kabupaten Pangandaran. Hal ini dilihat dari program pendidikan berkarakter yang terdapat pada lembaga pendidikan formal yaitu pada bidang agama, pramuka, dan seni budaya, serta pada upaya pelestarian seni tradisi yang dilakukan oleh pemerintah desa, kecamatan, serta kabupaten.

Gondang Buhun sebagai salah satu kegiatan ekstrakurikuler di sekolah maupun menjadi kegiatan Karang Taruna tidak hanya bertujuan untuk melestarikan seni tradisi, melainkan juga sebagai proses internalisasi nilainilai luhur seni tradisi Gondang Buhun bagi remaja dan masyarakat luas.
Berbagai upaya telah dilakukan untuk menjadikan seni tradisi Gondang Buhun sebagai media pendidikan karakter bagi remaja seperti dukungan pemerintah serta masyarakat setempat, namun terdapat juga kendala yang ditemukan yaitu anggapan sebagian remaja yang menganggap bahwa seni tradisi merupakan seni yang tidak sesuai dengan generasi muda. Untuk itu pemerintah setempat perlahan memberikan pemahaman tentang nilai-nilai luhur dalam seni Gondang Buhun serta melibatkan remaja menjadi pelaku seni tradisi Gondang Buhun.

Deskripsi tentang pendidikan karakter remaja melalui seni tradisi Gondang Buhun di Kabupaten Pangandaran ini diharapkan menjadi perhatian dan pertimbangan bagi pemerintah, masyarakat, serta semua pihak yang terkait pada pendidikan karakter melalui seni untuk terus melakukan upaya pelestarian nilai-nilai tradisi yang terdapat pada seni dan budaya sebagai kekayaan lokal yang dimiliki oleh daerah setempat.

\section{DAFTAR PUSTAKA}

Asmani, Jamal Ma'mur.

2013. Buku Panduan Internalisasi Pendidikan Karakter di Sekolah, Jogjakarta: DIVA Press.

Budimansyah, Dasim.

2010. Penguatan Pendidikan Kewarganegaraan untuk Membangun Karakter Bangsa, Bandung: Widya Aksara Press.

Elmubarok, Zaim. 
2008. Membumikan Pendidikan Nilai, Bandung: Alfabeta.

Kesuma, Dharma, dkk.

2011. Pendidikan Karakter: Kajian Teori dan Praktik di Sekolah. 